\title{
Applicability of a praxis-productive intervention program for children with phonological disorder
}

\begin{abstract}
Purpose: This study analyzed the applicability in the speech pathology clinic of a praxis-productive intervention program for children with phonological disorder, by its implementation. Methods: the study proposed a theoretical model of the program, based on a literature review on speech motor control, which orders muscle contraction for the execution of praxis, including the planning, preparation of movements and execution of plans, aiming at muscle contractions and movements of structures that ultimately lead to speech articulation. Thereafter, the material was applied to 12 children aged 6 to 8 years with phonological disorder, to show the applicability of the praxis-productive intervention program in practice. Results: the results showed improvement of speech in all individuals within the time defined by the instrument, with higher scores for the evaluative evidence of phonology and oral praxis after intervention compared to the scores before intervention. Conclusion: the praxis-productive intervention program was useful, simple easy to apply by the speech pathologist and well understood by the participants, with favorable responses for the acquisition of phonemes.
\end{abstract}

Keywords: speech, articulation disorder, motor skill, stomatognathic system, muscles, intervention studies
Volume 3 Issue 5 - 2018

\author{
Giannecchini T, Maximino L \\ Doctor of Speech Patology and Audiology, University of São \\ Paulo, Brazil
}

\begin{abstract}
Correspondence: Taisa Giannecchini, Doctor of Speech Patology and Audiology, University of São Paulo, Campus Bauru, Alameda Dr. Octávio Pinheiro Brisolla, 9-75,Vila Universitária - Vila Universitaria, Bauru Brazil, Tel (14)32358000/II,98357.9327,

Email taisagiannecchini@gmail.com, taisag@usp.br
\end{abstract}

Received: August 30, 2018 | Published: September 06, 2018

\section{Introduction}

The speech pathology clinic is continuously preparing to receive, support and re-educate individuals with communication disorders. Among the pathologies managed by this specialty, the speech disorders, either phonetic or phonological, present high and complex demands, thus requiring constant update of the professional and deepening on the theoretical questions related to speech execution and learning.

The speech is defined as the motor representation of language, in which there is coordination of three neurological processes: organization of concepts, formulation and symbolic expression; programming of the motor act involved in speech production; and the motor speech production proper. It requires adequate cognitive and phonological development and full integrity of the neurological system and orofacial structures. ${ }^{1}$

In 2004, a paper published in Brain $^{2}$ described a new brain area for the control of articulatory movements related to speech. Analyzing brains of individuals with articulatory planning disorder, by imaging studies, the authors observed that the same brain area, namely the insular lobe, exhibited an infraction i.e. a lesion. After this scientific landmark, this brain area was then recognized as the area of Dronkers, a new area involved in the motor planning of movements for oral verbal expression.

The motor control, which orders muscle contraction for speech execution, includes planning, preparation of movements and execution of plans, aiming at muscle contractions and displacements of structures that ultimately lead to the articulation of speech. ${ }^{3}$ In this sense, the phonological acquisition interacts with the development of motor speech control. ${ }^{4,5}$

Scientific studies published in the international literature suggest a new field of work in speech pathology, to manage the altered speech. In Brazil, the first scientific paper about orofacial praxis was published in 1996, ${ }^{6}$ whose authors highlight the need to stimulate this aspect for the clinical work with oral language. Expanding the national discussion, in 2015, the authors demonstrated that praxis disorders of the stomatognathic system are present in individuals with phonological disorders, and thus they should be stimulated to correct the clinical disorder. ${ }^{7}$

There is reference on the efficiency of myofunctional therapy for speech adequacy, regarding the improvement of musculature coordination in general. ${ }^{8}$ In the literature, any stimulus dedicated to the orofacial musculature provides better performance for the study population, for both phonological, phonetic and phoneticphonological disorders In the speech pathology clinic, there is consensus about the need to enhance the intervention programs in communication disorders.

Thus, the proposal of an intervention program, with predetermined number of sessions, presents a new material as a longitudinal and future result of this study, still recent and not very common in speech pathology practices. The present proposal of intervention assumes the integration of speech pathology abilities and the training of oral praxis. The hypothesis is that the stimulation of orofacial praxis, i.e. a sequence of exercises of lips and tongue, may enhance the learning of a new phoneme, as previously described in the literature, ${ }^{6,7}$ by optimizing the brain areas targeted to the coordination of movements for speech.

Several studies demonstrate the occurrence of praxis disorders of the stomatognathic system in speech alterations. ${ }^{6,9}$ Other authors ${ }^{10,11}$ point out that the language disorganization in phonological disorders may be influenced by the motor incapacity or by the praxis difficulty in the motor accomplishment of phonemes. Concerning the stimulation of orofacial praxis, in agreement with the literature, ${ }^{7,12}$ the program diagnosed praxis alterations in individuals with phonological disorder. 
These data were significant to provide foundation for the development of the PPIP and justify the inclusion of stimulation of orofacial praxis in the clinical work of speech pathologists when managing speech disorders.

Within this context, this study analyzed the applicability, in the speech pathology clinic, of a praxis-productive intervention program for children with phonological disorder, by its implementation.

\section{Methods}

This study was approved by the Institutional Review Board of University of São Paulo, under CAAE: 32126414.0.0000.5417. To design the praxis-productive intervention program, the specialized literature ${ }^{13}$ was surveyed for lips and tongue exercises, which were part of the motor stimulation and were combined with the stimulation of phonological aspects. The rationale to include the praxis aspects in the program followed a recent scientific study, ${ }^{14}$ which presents a theoretical panorama of this stimulation in the speech pathology clinic.

The program contained 8 stimulation sessions, with combined activities of phonological aspects with orofacial praxis of lips and tongue.

Subjects: The program was applied to 12 children aged 6 to 8 years, being 6 females and 6 males, enrolled in fundamental schools in the city of São Paulo, who spontaneously searched for speech pathology treatment at FMU-SP. Children of both genders were submitted to the praxis-productive intervention program (PPIP) composed of 12 sessions, applied by a speech pathologist trained for this procedure. One speech pathologist only selected the individuals according to the tests described below, as inclusion criteria. After selection, other speech pathologists, including the investigator, applied the PPIP in the individuals. Parents who agreed with participation in the study signed and informed consent form, then the child initiated the praxisproductive intervention program.

Inclusion criteria: the following inclusion criteria were considered: hearing assessment without peripheral alteration; absence of alteration in other aspects of language, either pragmatic, syntactic or semantic; absence of oromyofunctional alteration; absence of speech apraxia; presence of phonological alteration, i.e. phonological disorder; no previous speech pathology therapy until the evaluation.

The inclusion criteria were analyzed according to the following procedures: hearing evaluation - audiometry, vocal audiometry and tympanometry; evaluation of language in the morphosyntactic, semantic and pragmatic aspects; oromyofunctional evaluation to discard the alteration; anamnesis to rule out cases of speech apraxia; phonological evaluation by application of the Phonology Test of the $\mathrm{ABFW}^{15}$ for the diagnosis of phonological disorder, with imitation and naming tests; and no previous attendance in any speech pathology clinic, nor exposure to interventions to solve the speech alterations.

The Phonology Tests of the ABFW were used to evaluate the speech, and one different test to evaluate the different aspects of orofacial motricity. These parameters were used to analyze the outcomes with stimulation of the praxis-productive program proposed.

To use the ABFW, children were analyzed according to the number of phonological processes present at onset of intervention compared to the same number at completion of sessions.

The orofacial motricity was assessed by the Orofacial Praxis Test, ${ }^{16}$ in which the child is requested to perform (1a) verbal praxis, (1b) orofacial praxis, (2) sequence of movements, and (3) parallel movements, by request or imitation (ATTACHMENT A). Phonological stimulation was characterized by selection of the "Modified Cycles Model". ${ }^{17}$

At completion of this evaluation, the parents of children who met the inclusion criteria were informed that the PPIP would be applied for 12 weeks, after which the child would be re-evaluated and then the treatment would be continued by another speech pathologist at FMU center. Children not meeting the inclusion criteria were directly referred to traditional therapy in the same university clinic.

Procedure: The praxis-productive intervention program (PPIP) was composed of 12 sessions. Among these, 4 sessions addressed the evaluation of phonology and orofacial praxis, being 2 sessions before stimulation and 2 sessions after application of PPIP, as cited in the method. The orofacial praxis was stimulated by sequences of lips and tongue exercises, based on motor learning for 8 weeks. ${ }^{18}$ The phonological stimulation, which occurred simultaneously in all sessions, followed the "Modified Cycles Model". It was decided to perform one weekly session within the program, without extra exercises at home.

\section{Results}

Concerning the evaluations to which the individuals were submitted, the results were analyzed before and after intervention by the praxis-productive program proposed in the present investigation.

The results indicated significant results comparing the performance of individuals in all tests, i.e. in imitation and naming at study onset middle and completion (Tables 1) (Table 2).

Data on the evaluations of Phonology before and after intervention are presented in ATTACHMENTS B and C, characterizing the phonological processes evaluated per individual In the imitation at onset, the mean of altered phonological processes was 3.25 , compared to 1 at completion (Friedman test-repeated measures and analysis of variance) with $\mathrm{p}=0.001$ (Table 1 ). The individuals presented more altered phonological processes in imitation at onset compared to completion, indicating improved performance.

In naming at onset, the mean of altered phonological processes was 3.25 , compared to 1.16 at completion, with statistically significant difference with $\mathrm{p}=<0.001$ (Friedman) (Table 2). This revealed that the individuals had more altered phonological processes in naming at onset compared to completion.

The Orofacial Praxis Test analyzed the performance of individuals in each evaluation, before and after intervention. The results were separated into 6 variables, by number of correct responses: request before intervention, request after intervention, imitation before intervention and imitation after intervention, exercises not performed before intervention and exercises not performed after intervention. The paired test was applied for statistical analysis, which revealed significant results for all variables.

In the request before and after intervention, the change in performance achieved by treatment was statistically significant $(p=<0.001)$. In the request before intervention, the mean of completed exercises was 10.167 , which increased to 25.167 after intervention, indicating an increase in the number of completed exercises upon request, with improved performance in this test (Table 3 ).

In the imitation before and after intervention, there was statistically significant change in the performance achieved by treatment $(p=<$ 
0.001). The mean of exercises in imitation before intervention was 19.417, which was reduced to 8.167 after the intervention, indicating a decrease in the number of exercises performed by imitation, since the same exercises were then performed upon request (Table 4).

The same response was observed in exercises not performed in the evaluation before and after intervention, with statistically

Table 1 Attachment A-The Orofacial Praxis Test (Bearzotti, Tavano and Fabbro, 2007) significant change. Before intervention, when the individuals did not perform the exercises on the first evaluation, the mean of effectively performed exercises was 5.417, which was reduced to 1.167 after the intervention, indicating a decrease in the number of uncompleted exercises, since the same exercises were then performed without the need of imitation, highlighting the enhancement of skills in the individuals in this sample (Table 5).

\begin{tabular}{|c|c|c|c|c|c|}
\hline \multicolumn{4}{|c|}{ Items of the orofacial praxis test } & \multirow[b]{2}{*}{ Request } & \multirow[b]{2}{*}{ Imitation } \\
\hline la. verbal praxis & Request & Imitation & Ib. orofacial praxis & & \\
\hline \multicolumn{3}{|l|}{ Meowing } & Showing the tongue & & \\
\hline \multicolumn{3}{|l|}{ Bleating } & Clenching the teeth & & \\
\hline \multicolumn{3}{|l|}{ The train's noise } & Biting lower lip & & \\
\hline \multicolumn{3}{|l|}{ Saying "a" with the mouth open } & Blowing & & \\
\hline \multicolumn{3}{|l|}{ Coughing } & Blowing the cheeks & & \\
\hline \multicolumn{3}{|l|}{ Clearing the voice } & Touching the cheek wit & che tongue & \\
\hline \multicolumn{3}{|l|}{ Clicking the tongue } & Smiling & & \\
\hline \multicolumn{3}{|l|}{ Blowing a raspberry } & Yawning & & \\
\hline \multicolumn{3}{|l|}{ Asking for silence ("Shhhhhhh") } & Biting the tongue with & teeth & \\
\hline \multicolumn{3}{|l|}{ Humming a tone } & Breathing in through th & nose & \\
\hline \multicolumn{3}{|l|}{ Whistling } & Raising the eyebrows & & \\
\hline \multicolumn{3}{|l|}{ Blowing a kiss } & Blinking & & \\
\hline \multicolumn{6}{|l|}{ Total } \\
\hline \multicolumn{3}{|l|}{ 2. Sequence of movements } & 3. Parallel movements & & \\
\hline \multicolumn{3}{|l|}{ Opening and closing the mouth } & Closing the eyes and of & ning the mo & \\
\hline \multicolumn{3}{|c|}{ Showing the tongue and closing the mouth } & Closing the teeth and $r$ & ing the eyeb & ows \\
\hline \multicolumn{3}{|c|}{ Blowing the cheeks and blowing with the nose } & Biting the tongue, closir & the mouth & saying "Mm-mm" \\
\hline \multicolumn{3}{|c|}{ Showing the teeth, opening the mouth and closing the eyes } & Opening the mouth, pr & uding the to & gue and saying "ahhh" \\
\hline \multicolumn{3}{|c|}{ Blowing, biting the lower lip and blowing the cheeks } & Closing the eyes, closin & he mouth a & breathing in through the nose \\
\hline
\end{tabular}


Table 2 Attachment B - Characterization of phonological processes by individuals before the praxis-productive intervention program

\begin{tabular}{|c|c|c|c|c|c|c|c|c|c|c|c|c|}
\hline Individual & I & 2 & 3 & & 3 & 6 & 7 & $\mathbf{S}$ & 9 & ID & 0I:00 & 12 \\
\hline Gender, age & $M / 6.4$ & $M / 6.4$ & $=16 \mathrm{~L}$. & $=.16 \mathrm{~L}$ & & $\mathrm{~F} / 6.5$ & $M / 7.0$ & $M / 7.0$ & $M / 7.2$ & $\mathrm{~F} / 7.4$ & $=/ 7 \mathrm{~S}$ & $M / 8.0$ \\
\hline \multicolumn{13}{|l|}{ Phonological process } \\
\hline \multicolumn{13}{|l|}{ Consonantal harmony } \\
\hline \multicolumn{13}{|l|}{ Plosivation of fricatives } \\
\hline \multicolumn{13}{|l|}{ Velar backing } \\
\hline Palatal backing & $x$ & & & & & & & & & & & \\
\hline Velar fronting & $x$ & $x$ & $x$ & & & & & & & & & \\
\hline Palatal fronting & $x$ & $x$ & & & & & & & & & & \\
\hline Liquids simplification & $x$ & $x$ & $x$ & $x$ & $x$ & $x$ & & & $x$ & $x$ & $x$ & \\
\hline Cluster simplification & $x$ & $x$ & $x$ & & $x$ & $x$ & $x$ & & $x$ & $x$ & $x$ & $x$ \\
\hline Final consonant simplification & $x$ & $x$ & & $x$ & $x$ & $x$ & & & & & & \\
\hline \multicolumn{13}{|l|}{ Plosives voicing } \\
\hline \multicolumn{13}{|l|}{ Fricatives voicing } \\
\hline Plosives devoicing & & $x$ & $x$ & & & & $x$ & $x$ & $x$ & $x$ & & \\
\hline Fricatives & & $x$ & $x$ & & & & $x$ & $x$ & & $x$ & & $x$ \\
\hline Others & & & & $x$ & $x$ & $x$ & $x$ & $x$ & & $x$ & $x$ & $x$ \\
\hline Total & 6 & 7 & 5 & 3 & 4 & 5 & 3 & 3 & 3 & 5 & 3 & 3 \\
\hline
\end{tabular}

Table 3 Attachment C - Characterization of phonological processes by individuals after the praxis-productive intervention program

\begin{tabular}{|c|c|c|c|c|c|c|c|c|c|c|c|c|}
\hline Individual & $\mathbf{I}$ & 2 & 3 & 4 & 5 & 6 & 7 & $\mathbf{a}$ & 9 & 10 & 11 & 12 \\
\hline Gender, age & $M / 5.4$ & $M / 5.4$ & $F / 5.4$ & $\mathrm{~F} / 5.4$ & $F / 5.5$ & $F / 5.5$ & $M / 7.0$ & $\mathrm{M} / 7.0$ & $\mathrm{M} / 7.2$ & $\mathrm{~F} / 7.4$ & $\mathrm{~F} / 7.8$ & $M / 8.0$ \\
\hline \multicolumn{13}{|l|}{ Phonological process } \\
\hline \multicolumn{13}{|l|}{ Consonantal harmony } \\
\hline \multicolumn{13}{|l|}{ Plosivation of fricatives } \\
\hline \multicolumn{13}{|l|}{ Velar backing } \\
\hline \multicolumn{13}{|l|}{ Palatal backing } \\
\hline Velar fronting & $x$ & & & & & & & & & & & \\
\hline Palatal fronting & & $x$ & & & & & & & & & & \\
\hline Liquids simplification & & $x$ & & & & $x$ & & & & & & \\
\hline Cluster simplification & & $x$ & $x$ & & & $x$ & & & & $x$ & & \\
\hline Final consonant simplification & $x$ & & & & & & & & & & & \\
\hline \multicolumn{13}{|l|}{ Plosives voicing } \\
\hline \multicolumn{13}{|l|}{ Fricatives } \\
\hline Plosives devoicing & & & & $x$ & & & & $x$ & & & & \\
\hline \multicolumn{13}{|l|}{ Fricatives } \\
\hline \multicolumn{13}{|l|}{ devoicing } \\
\hline Others & & & & & & $x$ & & & & $x$ & & $x$ \\
\hline Total & 2 & 3 & 1 & 1 & $\mathrm{D}$ & 3 & 0 & 1 & I & 2 & 0 & 1 \\
\hline
\end{tabular}


Table 4 Comparison of performance in the phonology test of the ABFW imitation and Naming at the onset and completion of the praxis-productive intervention program.

\begin{tabular}{llll}
\hline Name of test applied & N & Mean & Standard deviation \\
\hline IMITATION - ONSET & 12 & 3.250 & 1.865 \\
IMITATION - COMPLETION & 12 & 1.000 & 1.279 \\
NAMING - ONSET & 12 & 3.250 & 1.865 \\
NAMIMG - COMPLETION & 12 & 1.167 & 1.267 \\
\hline
\end{tabular}

Legend $N$, number of participants; $\mathrm{p}=<0.001$

Table 5 Request and Imitation of movements in The Orofacial Praxis Test before and after the praxis-productive intervention program

\begin{tabular}{llll}
\hline Name of test applied & N & Mean & Standard deviation \\
\hline REQUEST - BEFORE & 12 & 10.167 & 7.004 \\
REQUEST - AFTER & 12 & 25.167 & 5.374 \\
IMITATION - BEFORE & 12 & 19.417 & 4.944 \\
IMITATION - AFTER & 12 & 8.167 & 5.078 \\
\hline
\end{tabular}

Legend $N$, number of participants; $\mathrm{p}=<0.001$

\section{Discussion}

The program was easy to apply, providing the details required for its accomplishment. The sessions were organized according to the described criteria, and the individuals with phonological disorder did not have difficulty to understand the orders provided by the speech pathologist trained to apply the instrument. The responses of individuals were recorded on their respective sheets, generating data that were statistically analyzed. The re-tests were always applied after the $4^{\text {th }}$ intervention session and provided relevant answers to measure the evolution of individuals in the sample, as well as their difficulties, and to evidence the usability of the program.

The time spent by individuals in the program was classified as "very good" and with "good effectiveness" by the children's caretakers, meeting their expectations. No caretaker or individual in the sample gave up the scheduled sessions.

It may be inferred that the program with determined sessions was beneficial for the individuals, concerning the time during which they were exposed to speech stimulation. Reports of treatment time for phonological disorders are mentioned in the literature, ${ }^{19,20}$ and in a document of the Brazilian Society of Speech-Language Pathology and Audiology (SBFa), entitled "Balizadores de Tempo de tratamento em Fonoaudiologia". ${ }^{21}$ These papers mention extensive therapy times, directly related to the severity of phonological disorder, with mean of 18 therapy sessions. In the SBFa document, which includes speech among the language alterations, the subtitle of specific articulation disorders mentions periods longer than 1 year to solve the alterations, with 2 weekly sessions of 45 minutes each. The program proposed in this study prioritized the aspects to be stimulated and achieved favorable results in all individuals in 12 sessions, confirming the hypothesis that motor learning may be achieved in 8 sessions.

Thus, a praxis-productive program was proposed, considering as priority:

a. The combination between stimulation of phonological aspects and motor aspects of speech; b. The praxis-productive stimulation in 8 sessions, based on the principles of muscular motor programming;

The combination of the two aspects contributed to overcome the phonological disorder in individuals in this sample, or at least to reduce the phonological processes expected for a determined age.

The goal of the present study has practical implication in the speech pathology clinic, by discussing the applicability of the program. Data collected in evaluations before and after intervention, concerning the performance of individuals, provide the theoretical support to justify the role this program may play in the clinical practice, even though it does not directly represent the instrument efficacy, due to the small number of individuals. Numerical data were used and will be discussed to indicate the usability of the PPIP in the several clinical manifestations of speech disorders.

Comparison of the performance of study individuals concerning the tests of Phonology, Naming and Imitation revealed that they all presented inadequate phonological processes for their age, thus they were included in the program (Tables 1) (Table 2); ATTACHMENT B). After the 8 stimulation sessions, all individuals reduced the number of inadequate phonological processes, being that 3 out of the 12 individuals had their oral production generalized, and thus normalized (ATTACHMENT C). Table 1 indicate improved performance in the execution of tests, i.e. lower occurrence of significant errors between all evaluations, which was greater comparing the initial and final tests. Therefore, the evaluation of individuals at the middle of the study, as a baseline, was effective to measure the changes in speech, which is important for the clinical practice and significant to indicate the applicability of the proposed program. It should be mentioned that the individuals included in the study presented alterations in different phonological processes, and all of them achieved positive outcomes, with partial or total elimination of alterations, indicating the possibility to use the PPIP for several types of phonological disorder.

The Orofacial Praxis Test $^{16}$ analyzed the performance of individuals in each evaluation, before and after intervention. For four study variables, namely request before intervention, request after intervention, imitation before intervention and imitation after intervention, the results were statistically significant, indicating better performance of individuals (Table 2). There was reduction in the number of exercises not performed before and after intervention. That is to say, the exercises could be performed after the intervention, assuring their praxis learning. It should be highlighted that some movements requested in the test were not specifically addressed in the session, i.e. the improvement achieved in these exercises was attained by the training of orofacial praxis that was part of the program.

Concerning the program, it should be mentioned that the coordination of exercises was qualitatively increased, as measured by the tests before and after intervention, demonstrating the applicability of PPIP for children with phonological disorders.

Confirming the assumption that phonological acquisition interacts with the speech motor control, 4,5 the program proposed in this study presented to be an instrument that, by considering these aspects, offers stimulation to enhance the acquisition of phonemes. The combination of phonological and motor stimulation ${ }^{22}$ was also demonstrated in program application, being more effective to overcome the articulation disorders.

It should be mentioned that the PPIP proposes a bimodal stimulation for speech adequacy. The positive results demonstrated 
in the literature were addressed by application of the Modified Cycles Model combined with the praxis stimulation, which the literature indicates as a necessary characteristic for speech production. However, in the present sample, it is not possible to state whether the muscle exercises employed in the program are individually effective, as also demonstrated by other authors ${ }^{23}$ about the muscle stimulation.

The present findings are unprecedented concerning the inclusion of stimulation of orofacial praxis in the clinical work on speech, especially for children with phonological disorders, highlighting the scientific relevance and theoretical basis for its execution. Meeting the clinical demands of phonological disorders is part of the tasks of speech pathologists, and this tool presents as a viable and useful tool for the reestablishment of function. The utilization of PPIP may be expanded for several presentations of phonological disorders. The program, which proposes intervention for individuals presenting disorders in different phonological processes, provided positive results for all participants.

The applicability of PPIP may only be considered in the combination of auditory and motor aspects, assuring the stimulation of stages of language reception and accomplishment. ${ }^{24}$

\section{Conclusion}

The praxis-productive intervention program (PPIP) designed for children with phonological disorders was composed of 12 sessions, being 8 of auditory stimulation and orofacial praxis of lips and tongue, and 4 sessions to evaluate these aspects before and after intervention. The application of PPIP indicated improvement of speech in all individuals, within the time established by the instrument, with higher scores in phonology evaluations and oral praxis after intervention compared to the scores before intervention, indicating its usability. The PPIP was useful, simple, easy to apply by the speech pathologists and well understood by the study subjects, with favorable responses in the acquisition of phonemes and consequently in the phonological and praxis development. Future studies should expand the sample, both in age and different types of speech disorders, to complement the present findings and allow the development of intervention programs to meet the clinical demands.

\section{Acknowledgments}

None.

\section{Conflict of interest}

The author declares no conflict of interest.

\section{References}

1. Douglas RC. Fisiologia aplicada a Fonoaudiologia. GuanababaKoogan. 2006.

2. Dronkers NF. A new brain region for coordinating speech articulation. Nature. 1996;384(6605):159-161.

3. Kent DR. Research on speech motor control and its disorders: A review and prospective. J Com Disorders. 2000;33(5):391-428.

4. Befi LDM, Pereira ACS, Bento AC. Representação fonológica em crianças com distúrbio específico de linguagem (DEL). Pró-Fono. 2010;22(3):305-310.

5. Mezzono CL, Mota HB, Dias RF. Desvio fonológico: aspectos sobre produção, percepção e escrita. Revista da Sociedade Brasileira de Fonoaudiologia. 2010;15(4):554-560
6. Farias SR, Ávila CRB, Vieira MM. Relação entre fala, tônus e praxia não-verbal do sistema estomatognático em pré-escolares. Pró-Fono $R$ Atual Cient. 2006;18(3):267-276.

7. Gubiani MB, Carli CM, Keske SM. Desvio fonológico e alterações práxicas orofacias e do sistema estomatognático. Rev CEFAC. 2015;17(1):134-142.

8. Costa PP, Mezzomo CL, Keske SM. Verificação da eficiência da abordagem terapêutica miofuncional em casos de desvio fonológico, fonético e fonético-fonológico. Rev CEFAC. 2013;15(6):1703-1711.

9. Bertagnolli APC, Gubian MB, Ceron M, et al. Orofacial praxis abilities in children with speech disorders. Int Arch Otorhinolaryngol. 2015;19(4):286-292.

10. Giacchini V, Mota HB, Mezzomo CL. Variáveis relevantes no processo terapêutico para a aquisição do onset complexo na fala de crianças com desvio fonológico. Revista CEFAC. 2012;19:17-26.

11. Marchesan IQ, Martinelli RLC. A fala nos diversos contextos da motricidade orofacial. IN: A fala nos diversos contextos da motricidade orofacial. Org Berrentin-Felix et al. Pulso. 2015.

12. Marini C. Habilidades práxicas orofacias em crianças com desvio fonológico evolutivo e com desenvolvimento fonológico típico. [Dissertação]. Santa Maria (RS): Universidade Federal de Santa Maria, Centro de Ciências da Saúde, Programa de Pós-Graduação nos dos Distúrbios da Comunicação Humana. 2010.

13. ABRAMO. Terapia Fonoaudiológica em Motricidade Orofacial. 2012.

14. Giannecchini T, Yacubian-FA, Maximino LP. Praxia não verbal na fonoaudiologia: revisão de literatura. Rev CEFAC. 2016; 18(5):1200 1208

15. Wertzner HF. Fonologia. In: Andrade CRF. ABFW-Teste de Linguagem Infantil nas Áreas de Fonologia, Vocabulário, Fluência e Pragmática. São Paulo: Pró-Fono. 2004;5-40.

16. Bearzotti F, Tavano A, Fabbro F. Developmental of orofacial praxis of children from 4 to 8 years of age. Percept Mot Skills.. 2007;104(3 pt 2):1355-1366

17. Tyler A, Edwards ML, Saxman J. Clinical application of two phonologically based treatment procedures. J Speech Hear Disord. 1987;52(4):393-409.

18. Cerqueira VZ, Assencio FVJ, Marchesan IQ. Avaliação da capacidade funcional dos músculos orofaciais do idoso com e sem prótese detária. Revista CEFAC. 2001;3(2):157-160.

19. Puglisi ML, Gândara JP, Giusti E, et al. É possível predizer o tempo de terapia das alterações específicas no desenvolvimento da linguagem? $J$ Soc Bras Fonoaudiol. 2012;24(1):57-61.

20. Melo RM, Wiethan FM, Mota HB. Tempo médio para a alta fonoaudiológica a partir de três modelos com base fonológica. Revista CEFAC. 2012;14(2):23-25.

21. http://www.fonoaudiologia.org.br/publicacoes/BALIZADOR\%20 DE\%20TEMPO.pdf

22. Giacchini V. Aplicação de modelos terapêuticos de base fonética fonológica utilizados para a superação das alterações de fala. Dissertação de Mestrado. Universidade federal de santa maria, Centro de ciências da saúde. programa em distúrbios da comunicação Humana. Santa Maria. 2009.

23. Ferreira TS, Mangilli LD, Sassi FC, et al. Exercício fonoaudiológico: revisão científica. J Soc Bras Fonoaudiol. 2011;23(3):303-307.

24. Muller CC, Narbona J. A linguagem da criança. aspectos normais e patológicos. $2^{\text {nd }}$ ed. Porto Alegre, Artmed. 2005. 